\title{
Novel thin bronchoscope with a 1.7-mm working channel for peripheral pulmonary lesions
}

\author{
M. Oki, H. Saka, C. Kitagawa, S. Tanaka, T. Shimokata, K. Mori and S. Kajikawa
}

ABSTRACT: In the present study, the authors evaluated the diagnostic utility of a novel thin bronchoscope with a 1.7-mm working channel for peripheral pulmonary lesions.

A total of 118 patients were included in this prospective study. Bronchoscopic examination was performed using a 5.9- $\mathrm{mm}$ standard bronchoscope. If no visible endobronchial lesion was found, transbronchial biopsies were performed with 1.5-mm biopsy forceps under fluoroscopic guidance and the bronchus were washed with $10-20 \mathrm{~mL}$ of saline solution, using a prototype 3.5-mm thin bronchoscope with a 1.7-mm working channel.

Endobronchial lesion was visualised with the standard bronchoscope in 16 patients, and the other 102 patients underwent biopsies with the thin bronchoscope. The mean bronchus levels reached with the standard bronchoscope and the thin bronchoscope were 2.3 and 4.3 generations, respectively. Endobronchial abnormality was revealed with the thin bronchoscope in a further 14 patients. Diagnostic material was obtained in 50 of 68 (74\%) patients with malignant disease and 18 of $30(60 \%)$ patients with benign disease. Four patients did not return to follow-up. The diagnostic yield was $57 \%$, even in lesions $<20 \mathrm{~mm}$. There were no major complications.

In conclusion, bronchoscopy using a 3.5- $\mathrm{mm}$ thin bronchoscope with a 1.7- $\mathrm{mm}$ working channel is useful and safe for the diagnosis of peripheral pulmonary lesions.

KEYWORDS: Bronchoscopy, lung cancer, peripheral pulmonary lesions, thin bronchoscope, transbronchial biopsy, ultrathin bronchoscope

ocalised peripheral pulmonary lesions are commonly encountered in clinical practice and frequently require tissue diagnoses to project a treatment plan. In the diagnosis of such lesions, bronchoscopy under fluoroscopic guidance has come into wide use as a simple, safe and readily available sampling technique. However, the diagnostic yield of bronchoscopy for peripheral pulmonary lesions has been reported to be limited, so the usefulness of conventional bronchoscopy is controversial [1-3].

Innovation in technology has permitted the development of some promising bronchoscopes, including those that are thinner than conventional types. A preliminary study suggested that the use of a thin bronchoscope (BF-3C40, 3.3-mm distal end diameter, 1.2-mm working channel diameter; Olympus, Tokyo, Japan) as an adjunct instrument to a standard bronchoscope increases the diagnostic yield by providing an accurate pathway to the peripheral pulmonary lesions [4]. However, transbronchial biopsy (TBB) using currently available biopsy forceps for the 1.2-mm working channel was not performed in that study; the role of the thin bronchoscope as a single method for diagnosing peripheral pulmonary lesions therefore remains unclarified. In addition, several investigators have indicated that the smallcalibre working channel (1.2 $\mathrm{mm})$ of now-available thin bronchoscopes is limited by insufficient specimen collection [5-7]. Therefore, the clinical application of thin bronchoscopy for the examination of peripheral pulmonary lesions in adult patients has been quite limited.

The use of a thin bronchoscope with a larger working channel for examining peripheral pulmonary lesions seems to be promising. The aim of the present study was to assess the utility of a novel thin bronchoscope with a 1.7-mm working channel in the diagnosis of peripheral pulmonary lesions.

\section{MATERIALS AND METHODS}

\section{Patients}

The current prospective study was approved by the institutional review board of the present

\section{AFFILIATIONS}

Dept of Respiratory Medicine, Nagoya Medical Center, Nagoya, Japan.

CORRESPONDENCE

M. Oki

Dept of Respiratory Medicine

Nagoya Medical Center

4-1-1 Sannomaru

Naka-ku

Nagoya 460-0001

Japan

Fax: 81529510664

E-mail: Masahideo@aol.com

\section{Received:}

December 152007

Accepted after revision:

March 282008

STATEMENT OF INTEREST

A statement of interest for

this study can be found at www.erj.ersjournals.com/misc/ statements.shtml 
authors' hospital and informed consent was obtained from all patients. Between March 2005 and March 2006, 118 patients with localised peripheral pulmonary lesions, such as a solitary pulmonary nodule, a pulmonary mass or a localised infiltrate, who were referred for diagnostic bronchoscopy were enrolled. Patients with diffuse pulmonary lesions were excluded.

\section{Procedures}

All bronchoscopic procedures were performed by staff pulmonologists or supervised pulmonary residents of the present authors' institution, using conscious sedation with bolus IV midazolam and topical anaesthesia with lidocaine. A 7.5-mm inner diameter endotracheal tube was placed transorally under bronchoscopic control using a standard bronchovideoscope (BF-240 or BF-1T260, 5.9-mm distal end diameter; Olympus; fig. 1a), as used by IKEDA et al. [8] who developed the flexible bronchoscope. Bronchoscopy was then performed in the standard fashion to examine the endobronchial region. If an endobronchial lesion (e.g. exophitic endobronchial mass, submucosal spread or a peribronchial tumour causing extrinsic compression) was detected, tissue sampling was performed using the standard bronchoscope and the examination was then terminated. If no endobronchial lesion was observed, the standard bronchoscope was exchanged for a thin bronchoscope (XBF-3B40Y1 (hereafter referred to as 3B40); Olympus; fig. $1 \mathrm{~b}$ ) to examine peripheral pulmonary lesions. The 3B40 bronchofibrescope has a $3.5-\mathrm{mm}$ distal end diameter, a $1.7-\mathrm{mm}$ working channel diameter, a $180^{\circ}$ up and $130^{\circ}$ down angulation, a $90^{\circ}$ field of view and a 2-50-mm depth of field. The 3B40 was advanced toward the bronchus most likely leading to the lesion under direct vision. Once the 3B40 was inserted and wedged into the peripheral bronchus as far as possible, TBB using 1.5-mm forceps (FB-32D or XBO1-951; Olympus) was performed under fluoroscopic guidance. Eight biopsy specimens were taken from each lesion and each specimen was then transferred into separate containers filled with formalin for histological examination. After TBB, washing of the corresponding bronchus was performed with 10-20 mL of saline solution. The retrieved washing fluid was submitted for cytological examination and culture. Other procedures, such as brushing, curettage or needle aspiration biopsy for the target lesion, were not performed in the same setting. A chest

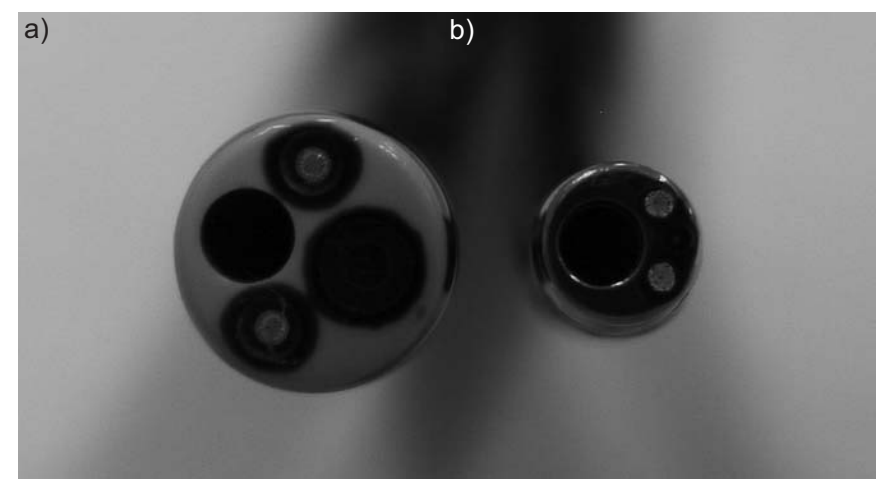

FIGURE 1. a) Standard bronchoscope with a distal end diameter of $5.9 \mathrm{~mm}$ and a working channel of $2.0 \mathrm{~mm}$ (BF-240; Olympus, Tokyo, Japan). b) Thin bronchoscope with a distal end diameter of $3.5 \mathrm{~mm}$ and a working channel of $1.7 \mathrm{~mm}$ (XBF-3B40Y1; Olympus). radiograph was obtained routinely to identify pneumothorax after the procedures. The number of bronchial generations of the standard or thin bronchoscope inserted was recorded. The number of the bronchial generations, as defined in [9], was as follows. 0: main bronchi; I: lobar bronchi; II: segmental bronchi (e.g. $\left.\mathrm{B}^{1}, \mathrm{~B}^{2}\right)$; III: subsegmental bronchi (e.g. $\left.\mathrm{B}^{1} \mathrm{a}, \mathrm{B}^{1} \mathrm{~b}\right)$; IV: subsubsegmental bronchi (e.g. $\mathrm{B}^{1}$ ai, $\mathrm{B}^{1}$ aii); and V: subsubsubsegmental bronchi (e.g. $\mathrm{B}^{1}$ ai $\alpha, \mathrm{B}^{1}$ ai $\beta$ ).

\section{Diagnosis}

All malignant diagnoses were confirmed pathologically, with the exception of that of a patient with peripheral T-cell lymphoma in whom the pulmonary lesion disappeared after chemotherapy. Benign diagnoses were established using surgical procedure, microbiological analysis, including tuberculosis or nontuberculous mycobacteriosis, or clinical followup. The lesions that obviously diminished or disappeared during the follow-up period were considered to be inflammation. Other benign diagnoses were confirmed via radiological size stability and clinical compatibility during the follow-up period, for $\geqslant 18$ months after bronchoscopy.

\section{Statistical analysis}

Means and percentages are presented as appropriate. Accuracies were calculated using standard definitions. Results were considered statistically significant when $p \leqslant 0.05$.

\section{RESULTS}

Endobronchial lesions were visualised using the standard bronchoscope in 16 patients; the other 102 patients underwent biopsies with the 3B40. Four patients were lost to follow-up. Thus, a total of 98 patients ( 55 males and 43 females; mean age 65.1 (range 36-82) yrs) with peripheral pulmonary lesions (median size $30.5 \mathrm{~mm}$, mean \pm SD size $34.3 \pm 16.8 \mathrm{~mm}$ (range 11-76 mm)) were included in the final analysis. The characteristics of the patients are presented in table 1.

The final diagnoses and the results of thin bronchoscopy are shown in table 2. Diagnostic material was obtained using the 3B40 in 50 out of $68(74 \%)$ patients with malignant disease, 18 out of $30(60 \%)$ patients with benign disease, and 68 out of 98

\section{TABLE 1 Characteristics of the patients and lesions}

$\begin{array}{lc}\text { Patients } & 98 \\ \text { Sex } \mathbf{M} / \mathbf{F} & 55 / 43 \\ \text { Age } \mathbf{y r s} & 65.1 \pm 10.9 \\ \text { Current smokers \% } & 36.7 \\ \text { Lesion size } \mathbf{~ m m} & 34.3 \pm 16.8 \\ \text { Lesion }<\mathbf{2 0} \mathbf{~ m m} & 23 \\ \text { Lesion } \geqslant \mathbf{2 0} \mathbf{~ m m} & 75 \\ \text { Location } & \\ \text { Right upper lobe } & 35 \\ \text { Right middle lobe } & 5 \\ \text { Right lower lobe } & 24 \\ \text { Left upper lobe } & 18 \\ \text { Lingula } & 5 \\ \text { Left lower lobe } & 11\end{array}$

Data are presented as $\mathrm{n}$ or mean $\pm \mathrm{SD}$ unless otherwise stated. $\mathrm{M}$ : male; $\mathrm{F}$ female. 


\begin{tabular}{|c|c|c|c|}
\hline \multirow{2}{*}{$\begin{array}{l}\text { TABLE } 2 \\
\text { Diagnosis }\end{array}$} & \multicolumn{3}{|c|}{$\begin{array}{l}\text { Final diagnoses and results of thin } \\
\text { bronchoscopy in } 98 \text { patients }\end{array}$} \\
\hline & & $\begin{array}{l}\text { Patients in } \\
\text { trial }\end{array}$ & $\begin{array}{l}\text { Patients with diagnosis } \\
\text { by thin bronchoscopy }\end{array}$ \\
\hline \multicolumn{4}{|l|}{ Malignant } \\
\hline Adenocaro & oma & 37 & 28 (76) \\
\hline Squamous & ell carcinoma & 15 & $13(87)$ \\
\hline Large cell & rcinoma & 3 & $2(67)$ \\
\hline Bronchiolo & veolar carcinoma & 2 & 0 \\
\hline Nonsmall & II carcinoma & 6 & $4(67)$ \\
\hline Small cell & rcinoma & 2 & $1(50)$ \\
\hline Metastasis & & 1 & $1(100)$ \\
\hline Malignant & nphoma & 2 & $1(50)$ \\
\hline \multicolumn{4}{|l|}{ Benign } \\
\hline Tuberculos & & 6 & $4(67)$ \\
\hline Nontuberc & ous mycobacteriosis & 4 & $4(100)$ \\
\hline Pneumoco & osis & 2 & $2(100)$ \\
\hline Bacterial $p$ & umonia & 2 & $2(100)$ \\
\hline Organising & neumonia & 1 & $1(100)$ \\
\hline Cryptococ & & 1 & $1(100)$ \\
\hline Amyloidos & & 1 & $1(100)$ \\
\hline Pulmonary & bscess & 1 & 0 \\
\hline Hamartom & & 1 & 0 \\
\hline Wegener's & ranulomatosis & 1 & 0 \\
\hline Inflammati & & 6 & $3(50)$ \\
\hline \multicolumn{4}{|c|}{ Benign lesions } \\
\hline clinically $\mathrm{c}$ & firmed & 4 & 0 \\
\hline Total & & 98 & $68(69)$ \\
\hline
\end{tabular}

(69\%) patients overall. TBB was diagnostic in 49 (72\%) patients with malignant disease and $15(50 \%)$ patients with benign disease, whereas the cytological specimen from washing was positive in $11(16 \%)$ patients with malignant disease, and the culture from washing provided diagnosis in nine $(30 \%)$ patients with benign disease. Washing alone provided diagnosis in four patients (adenocarcinoma in one, tuberculosis in two, and nontuberculous mycobacteriosis in one). The sensitivity, specificity, negative predictive value, positive predictive value and accuracy of the thin bronchoscopy for diagnosing malignancy were 74, 100,63, 100 and 82\%, respectively.

\begin{tabular}{llll} 
TABLE 3 & \multicolumn{2}{c}{$\begin{array}{l}\text { Diagnostic yield of thin bronchoscopy according } \\
\text { to lesion size }\end{array}$} \\
Lesion size & \multicolumn{2}{c}{ Lesions diagnosed/lesions examined } \\
\cline { 2 - 4 } & Malignant & Benign & Total \\
\hline & $10 / 13(77)$ & $3 / 10(30)$ & $13 / 23(57)$ \\
$\geqslant \mathbf{2 0} \mathbf{~ m m}$ & $40 / 55(73)$ & $15 / 20(75)$ & $55 / 75(73)$ \\
Total & $50 / 68(74)$ & $18 / 30(60)$ & $68 / 98(69)$ \\
\hline
\end{tabular}

Data are presented as $n(\%)$. Using the Chi-squared test, $p=0.13$ between the diagnostic yield for the lesions $<20 \mathrm{~mm}$ and $\geqslant 20 \mathrm{~mm}$ in size.
Table 3 shows the diagnostic yield of thin bronchoscopy related to the lesion size, which was determined by measuring the greatest diameter on computed tomography (CT). Diagnostic yield of thin bronchoscopy for lesions $<20 \mathrm{~mm}$ and $\geqslant 20 \mathrm{~mm}$ in size was $57 \%$ (13 out of 23 ) and $73 \%$ (55 out of $75)$, respectively. The diagnostic yield was not significantly different in terms of the lesion size $(p=0.13$ using the Chisquared test).

The 3B40 could be inserted into more distal bronchi compared to the standard bronchoscope (mean \pm SD generations $4.3 \pm 1.0$ versus $2.3 \pm 1.0 ; \mathrm{p}<0.001$ using a paired t-test; fig. 2 ). An endobronchial abnormality that could not be visualised with
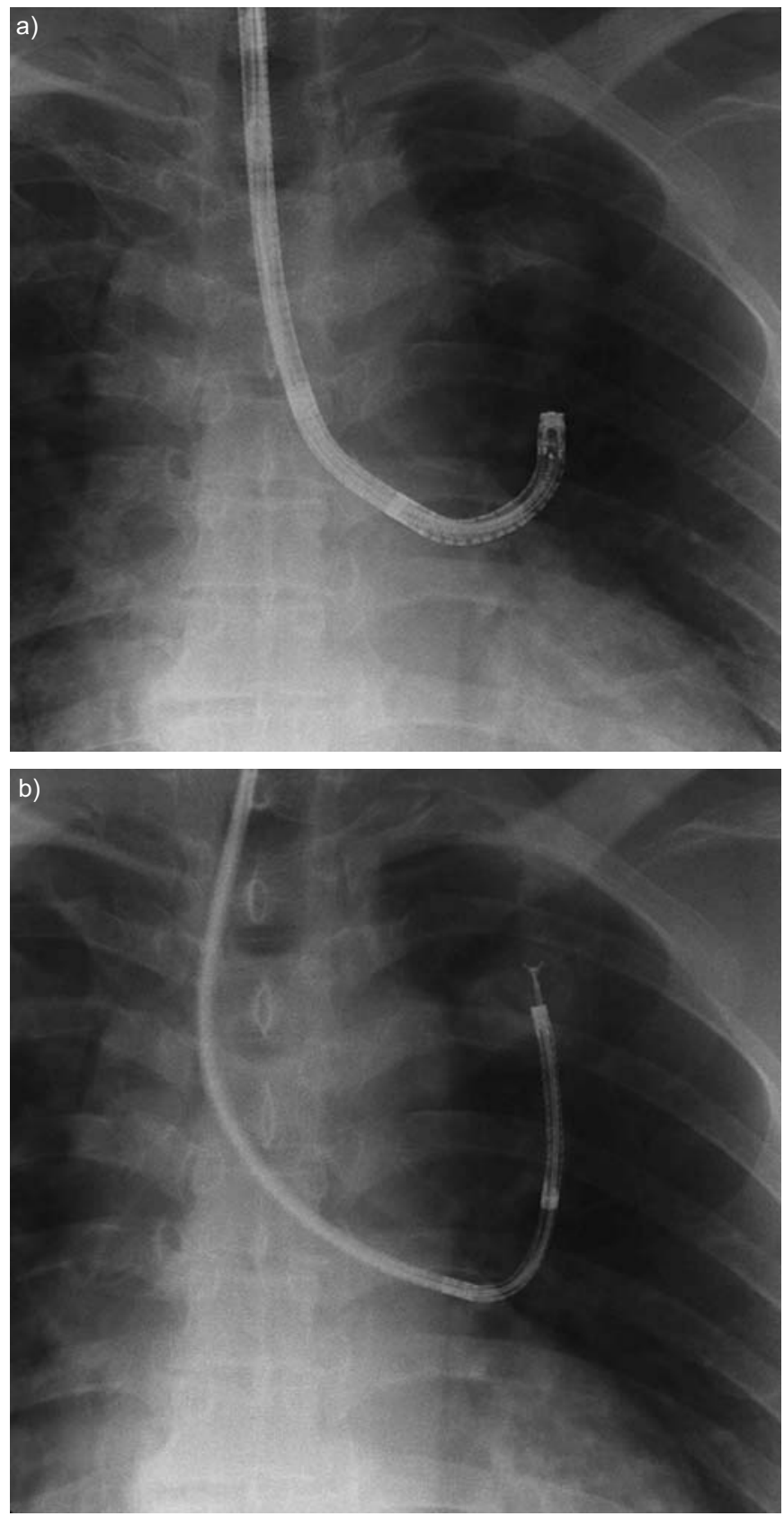

FIGURE 2. Fluoroscopic images using a) the standard bronchoscope and b) XBF-3B40Y1 (Olympus, Tokyo, Japan). 


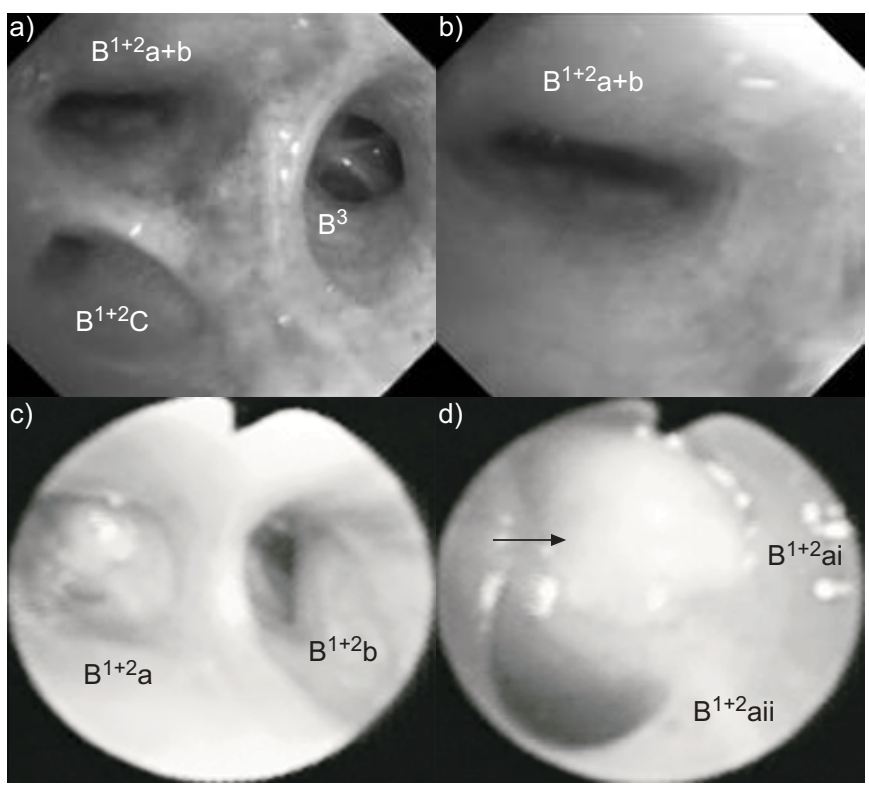

FIGURE 3. a) and b) Standard bronchoscopic views of left upper lobe bronchus. b) The standard bronchoscope could be inserted as far as the subsegmental bronchus $\left(B^{1+2} a+b\right)$. $B^{3}$ : anterior segment of the left upper lobe; $B^{1+2} a+b$ and $B^{1+2} C$ : the third generation bronchus of apical posterior segment of the left upper lobe. c) and d) Thin bronchoscopic views of more distal bronchi. d) Endobronchial tumour (adenocarcinoma; arrow) of the fourth generation bronchus $\left(\mathrm{B}^{1+2}\right.$ ai) was revealed. $\mathrm{B}^{1+2} \mathrm{a}$ and $\mathrm{B}^{1+2} \mathrm{~b}$ : the third generation bronchus of apical posterior segment of the left upper lobe; $B^{1+2}$ ai and $B^{1+2}$ aii: the fourth generation bronchus of apical posterior segment of the left upper lobe.

a standard bronchoscope was revealed with the 3B40 in 14 patients (14\%; fig. 3). Diagnostic yield was not affected by the location of the lesion ( $p=0.68$ using the Chi-squared test; table 4).

There were no significant complications, such as major bleeding or pneumothorax.

\section{DISCUSSION}

The present results indicate that bronchoscopy using a 3.5-mm thin bronchoscope with a 1.7-mm working channel is useful as a single method for the diagnosis of peripheral pulmonary lesions. The thin bronchoscope can enter a further two distal generations of bronchi from the bronchi reached by a $5.9-\mathrm{mm}$ standard bronchoscope; it is thus likely to increase the diagnostic yield. The yield of thin bronchoscopy was as high as $69 \%$, and $57 \%$ in lesions $<20 \mathrm{~mm}$.

Over the past three decades, flexible bronchoscopy with or without fluoroscopic guidance has been commonly used to evaluate various pulmonary lesions [8, 10]. It is a recommended procedure for endoscopically visible central lesions because of its high diagnostic yield [11]. The role of the conventional procedure for the evaluation of peripheral pulmonary lesions is controversial [1-3]. The diagnostic yield for peripheral pulmonary lesion varies widely in the literature, between $20-80 \%$, and depends on the size of the lesion [12-16]. In a recent review article, the sensitivity of conventional bronchoscopy for peripheral bronchogenic carcinoma $<20 \mathrm{~mm}$ was reported to be $34 \%$, and was $63 \%$ for peripheral
TABLE 4 Diagnostic yield and inserted bronchial generation of thin bronchoscopy in relation to bronchopulmonary segments

\begin{tabular}{lcccc} 
Segments & $\begin{array}{c}\text { Bronchial generation } \\
\text { inserted }\end{array}$ & \multicolumn{3}{c}{ Lesions diagnosed/lesions examined } \\
\cline { 3 - 5 } & & Malignant & Benign & Total \\
\hline RUL & $4.5 \pm 1.0$ & $17 / 22(77)$ & $8 / 13(62)$ & $25 / 35(71)$ \\
RML & $4.2 \pm 1.3$ & $3 / 4(75)$ & $0 / 1(0)$ & $3 / 5(60)$ \\
RLL & $4.0 \pm 0.8$ & $8 / 14(57)$ & $6 / 10(60)$ & $14 / 24(58)$ \\
LUL & $4.4 \pm 1.1$ & $12 / 17(71)$ & $1 / 1(100)$ & $13 / 18(72)$ \\
Lingula & $4.4 \pm 1.1$ & $2 / 3(67)$ & $2 / 2(100)$ & $4 / 5(80)$ \\
LLL & $4.5 \pm 0.9$ & $8 / 8(100)$ & $1 / 3(33)$ & $9 / 11(82)$ \\
\hline
\end{tabular}

Data are presented as mean \pm SD or $n(\%)$. RUL: right upper lobe; RML: right middle lobe; RLL: right lower lobe; LUL: left upper lobe; LLL: left lower lobe. Using the Chi-squared test, $p=0.68$ across diagnostic yield in the locations of the lesions.

bronchogenic carcinoma $>20 \mathrm{~mm}$ [11]. The conventional bronchoscope can be inserted only as far as the segmental or subsegmental bronchus. Therefore, inserting and advancing instruments such as biopsy forceps or a cytology brush into the angled bronchial branch is often difficult. Thin bronchoscopy has the distinct advantage of manoeuvrability for selecting a target bronchus that may lead to a lesion. Moreover, a lesion invisible to standard bronchoscopy was visualised with the $3 \mathrm{~B} 40$ in $14 \%$ of patients. In the present study, the sensitivity of thin bronchoscopy in patients with malignant lesions $<20 \mathrm{~mm}$ and $\geqslant 20 \mathrm{~mm}$ in size was $77 \%$ and $73 \%$, respectively. Although the present study was not designed specifically to compare the diagnostic yields of thin and conventional bronchoscopy, thin bronchoscopy seems to offer improved diagnostic yield compared to conventional bronchoscopy.

Although the application of a thin bronchoscope in adults is not a novel idea [8, 17], only a few small studies have addressed the role of thin bronchoscopy for evaluating localised peripheral pulmonary lesions [4, 6, 18-20]. The 3.3$\mathrm{mm}$ thin bronchoscope (BF-3C40) was reportedly a useful adjunct to conventional bronchoscopy in the diagnosis of peripheral pulmonary lesions [4]. In the study of ROONEY et al. [4], a total of 17 patients with peripheral lesions underwent bronchoscopy using the BF-3C40, followed by the use of a standard bronchoscope. The diagnostic yield of TBB with standard bronchoscopy under fluoroscopic guidance, which followed the same bronchial route to the lesion established by the BF-3C40, was $65 \%$ (11 out of 17 ) in all patients examined and $70 \%$ (seven out of 10 ) in patients with lesions $<30 \mathrm{~mm}$ in size. Direct visualisation of the lesion was achieved with the BF-3C40 in $24 \%$ of patients (four out of 17). The major technical limitation of this method may be the difficulty in manoeuvring the biopsy forceps through the standard bronchoscope to follow the same bronchial route explored with the thin bronchoscope. Unfortunately, TBB using the BF-3C40 and biopsy forceps for a 1.2-mm working channel was not performed in that study, so the role of thin bronchoscopy alone was not assessed. Another study using a $2.8-\mathrm{mm}$ ultrathin bronchoscope with a 1.2-mm working channel 
demonstrated that TBB under fluoroscopic guidance using an ultrathin bronchoscope provided a higher diagnostic yield than that using a standard bronchoscope (60\% versus $54 \%$ ) [6]. YАМАМОтО et al. [6] described ultrathin bronchoscopy only as a useful adjunct to but not an alternative to conventional bronchoscopy, because sufficient material for the histological specimen cannot always be obtained with forceps for a 1.2-mm working channel. Most of the thin bronchoscopes now available incorporate a 1.2-mm working channel, and various instruments, such as biopsy forceps or a cytology brush, which can be passed through the 1.2-mm working channel, are available. However, the small-calibre working channel or miniaturised instruments have some functional drawbacks, including poor suction capability or inadequate specimen collection [5-7]. Therefore, the clinical application of thin or ultrathin bronchoscopy for diagnosing peripheral pulmonary lesions has been limited. The major advantages of the 3B40 over conventional thin bronchoscopes with a 1.2-mm working channel are its adequate suction performance or larger instrument compatibility due to the $1.7-\mathrm{mm}$ working channel incorporated. The forceps for a 1.7-mm channel are stouter and have greater manoeuvrability than the forceps for a $1.2-\mathrm{mm}$ channel. The present authors were satisfied with the size and quality of the sampling specimen using the forceps for pathological examination. The 3B40 could therefore be a useful alternative to a standard bronchoscope for examining peripheral pulmonary lesions.

The diagnostic yield of washing for peripheral malignant lesions using standard bronchoscopes has been reported to range $13-52 \%[15,21-23]$, and the usefulness of cytological examination of bronchial washings in addition to TBB is controversial [24]. The present study's yield (16\%) of bronchial washing using the thin bronchoscope seems to be low. This could be due to the low retrieval of instilled saline during procedures. The small peripheral bronchi with soft walls readily caused the thin bronchoscope to collapse under bronchoscopic suction. Therefore, instilled saline tends to be trapped in the more peripheral bronchi. This safe, inexpensive and minimal time-consuming procedure during thin bronchoscopy cannot be abandoned, because the cytological specimen from washing was the sole diagnostic specimen in one patient with adenocarcinoma. Technical improvements, such as using larger amounts of saline solution [23] or applying low-pressure suction, would be needed to increase the yield.

Recently, in an effort to increase the diagnostic yield of bronchoscopy for peripheral pulmonary lesions, several ancillary technologies have been proposed, such as multiplanar reconstruction (MPR) [25], electromagnetic navigation bronchoscopy (ENB) [26-31], virtual bronchoscopic navigation $[5,7]$, CT fluoroscopy $[32,33]$ and endobronchial ultrasound (EBUS) [31, 34-39], as well as thin bronchoscopy. The effects of these modalities during bronchoscopy are as follows: 1) mapping and navigation; 2) arrival verification of bronchoscopic instruments; and 3) bronchoscopic manoeuvrability.

The selection of the most appropriate bronchus for TBB from pre-procedural static images, such as chest radiography or standard CT imaging, is often difficult. Modifications in CT technology have permitted the development of helical CT with MPR, which provides every desired axis image of the lung.
MPR imaging can be used as a bronchial map that allows selection of an appropriate bronchial route to the peripheral pulmonary lesions. Additional MPR and rapid on-site evaluation using ultrafast Papanicolaou stain was reported to increase the diagnostic yield of bronchoscopy for the peripheral pulmonary lesions from 58 to $91 \%$ [25]. More recently, several navigation systems have been developed as guiding tools to reach the target lesions. An electromagnetic navigation system (superDimension/Bronchus; superDimension Ltd, Hertzliya, Israel), which creates an electromagnetic field around the chest and localises a steerable navigation catheter with an electromagnetic sensor overlaid upon previously acquired CT images, is a useful method for assisting in the localisation of the peripheral pulmonary lesions during bronchoscopy [26]. The diagnostic yield of ENB for peripheral pulmonary lesions has been reported to range 59-74\% [27-31]. Furthermore, several investigators [28, 29, 31] have indicated that the diagnostic yields of ENB were independent of lesion size or location. The virtual bronchoscopic navigation system (Olympus) automatically produces virtual bronchoscopy (VB) images of the bronchus leading to the lesions, which are reconstructed from helical CT data [7]. The bronchoscope is advanced to the target lesion, comparing the VB images and the actual bronchoscopic images simultaneously, so bronchoscopic visibility, insertability and manoeuvrability in the peripheral bronchi are important during the procedure. A few pilot studies have shown the usefulness of ultrathin bronchoscopy with this system for evaluating peripheral pulmonary lesions [5, 7]. The diagnostic yield of ultrathin bronchoscopy using this system, radiographic fluoroscopy, and/or CT fluoroscopy for the peripheral pulmonary lesions, reportedly averaged $65-82 \%[5,7]$, irrespective of the size of the lesions. Fluoroscopy-guided TBB is a common and simple bronchoscopic procedure for patients with peripheral pulmonary lesions. However, the two-dimensional image of fluoroscopy produces overlapping structures or instruments. Thus, accurately confirming that the forceps has reached the lesion is often difficult, even if the positions of the instrument and the target lesion are confirmed three-dimensionally, either by rotating the patient or the arm of a C-arm fluoroscope. CT fluoroscopy or EBUS allows precise verification of whether a bronchoscopic tool has reached the lesions, even if they are fluoroscopically invisible [39]. A comparative study demonstrated that the diagnostic yield of bronchoscopy under CT fluoroscopic guidance was higher than that of radiographic fluoroscopic guidance (62 versus 53\%) [32]. However, CT fluoroscopic guidance has the disadvantage of excessive radiation exposure for patients and staff. To overcome this disadvantage, the usefulness of dose-reduction CT fluoroscopy has been reported [33]. EBUS using a radial probe is also a useful adjunct to conventional bronchoscopy in order to increase the diagnostic yield for peripheral pulmonary lesions. The diagnostic yield of EBUS has been reported to range 58$80 \%$ [30, 34-39]. This method is particularly useful for small lesions and provides a high diagnostic yield of $70 \%$ even for fluoroscopically invisible lesions [39]. Recent lung cancer guidelines recommend bronchoscopy with EBUS, as available, for the diagnosis of small peripheral pulmonary lesions [11].

Interestingly, these modalities were likely to be complementary in increasing the diagnostic yield. A randomised 
controlled trial [31] demonstrated that the diagnostic yield of EBUS, ENB and the combination of EBUS and ENB for peripheral pulmonary lesions was $69 \%, 59 \%$ and $88 \%$, respectively. Although a guide catheter with double-hinged curette [35-37] or a dedicated steerable device [26-31] has often been used to overcome the difficulties of introducing and advancing the biopsy instrument to the area of interest, a thin bronchoscope with good bronchial selectivity and smooth manoeuvrability in the peripheral airway may perform the procedure easily and simply. The combination of thin bronchoscopy with the 3B40 and newer imaging guidance techniques may enhance the diagnostic yield.

Although it is usually mild, the complication rate of pneumothorax and bleeding related to the TBB with standard forceps has been reported to be $1-5 \%$ and $9 \%$, respectively [40]. Fortunately, such complications were not observed during the study periods of the present work. The size of the forceps for the 3B40 is slightly smaller than that for the standard bronchoscope with a 2-mm working channel. Although complications may occur even if small forceps are used [41], TBB with $3 \mathrm{~B} 40$ and the dedicated forceps may reduce the risk or the severity of complications such as pneumothorax or bleeding. Furthermore, a recent study suggested that thin bronchoscopy with the 3B40 was better tolerated than with standard bronchoscopy [42].

In conclusion, bronchoscopy using a $3.5-\mathrm{mm}$ thin bronchoscope with a 1.7-mm working channel is useful and safe for the diagnosis of peripheral pulmonary lesions. Moreover, it is a useful alternative to a standard bronchoscope for examining peripheral pulmonary lesions. In future applications, through combination with imaging guidance techniques, such as endobronchial ultrasound or bronchoscopic navigation, the yield of this procedure may be even further enhanced.

\section{REFERENCES}

1 Torrington KG, Kern JD. The utility of fiberoptic bronchoscopy in the evaluation of the solitary pulmonary nodule. Chest 1993; 104: 1021-1024.

2 Ost D, Fein AM, Feinsilver SH. The solitary pulmonary nodule. N Engl J Med 2003; 348: 2535-2542.

3 Tan BB, Flaherty KR, Kazerooni EA, Iannettoni MD. The solitary pulmonary nodule. Chest 2003; 123: Suppl. 1, 89S-96S.

4 Rooney CP, Wolf K, McLennan G. Ultrathin bronchoscopy as an adjunct to standard bronchoscopy in the diagnosis of peripheral lung lesion: a preliminary report. Respiration 2002; 69: 63-68.

5 Shinagawa N, Yamazaki K, Onodera Y, et al. CT-guided transbronchial biopsy using an ultrathin bronchoscope with virtual bronchoscopic navigation. Chest 2004; 125: 1138-1143.

6 Yamamoto S, Ueno K, Imamura F, et al. Usefulness of ultrathin bronchoscopy in diagnosis of lung cancer. Lung Cancer 2004; 46: 43-48.

7 Asano F, Matsuno Y, Shinagawa N, et al. A virtual bronchoscopic navigation system for pulmonary peripheral lesions. Chest 2006; 130: 559-566.

8 Ikeda S, Tsuboi E, Ono R, Ishikawa S. Flexible bronchofiberscope. Jpn J Clin Oncol 1971; 1: 55-65.
9 The Japan Lung Society. Classification of Lung Cancer. 1st English Edn. Tokyo, Kanehara \& Co. Ltd, 2000.

10 Sackner MA. Bronchofiberscopy. Am Rev Respir Dis 1975; 111: 62-88.

11 Rivera MP, Mehta AC. Initial diagnosis of lung cancer: ACCP evidence-based clinical practice guidelines (2nd edition). Chest 2007; 132: Suppl. 3, 131S-148S.

12 Ellis JH Jr. Transbronchial lung biopsy via the fiberoptic bronchoscope: experience with 107 consecutive cases and comparison with bronchial brushing. Chest 1975; 68: 524-532.

13 Wallace JM, Deutsch AL. Flexible fiberoptic bronchoscopy and percutaneous needle lung aspiration for evaluating the solitary pulmonary nodule. Chest 1982; 81: 665-671.

14 Gasparini S, Ferretti M, Secchi EB, Baldelli S, Zuccatosta L, Gusella P. Integration of transbronchial and percutaneous approach in the diagnosis of peripheral pulmonary nodules or masses: experience with 1,027 consecutive cases. Chest 1995; 108: 131-137.

15 Reichenberger F, Weber J, Tamm M, et al. The value of transbronchial needle aspiration in the diagnosis of peripheral pulmonary lesions. Chest 1999; 116: 704-708.

16 Baaklini WA, Reinoso MA, Gorin AB, Sharafkaneh A, Manian P. Diagnostic yield of fiberoptic bronchoscopy in evaluating solitary pulmonary nodules. Chest 2000; 117: 1049-1054.

17 Prakash UB. The use of the pediatric fiberoptic bronchoscope in adults. Am Rev Respir Dis 1985; 132: 715-717.

18 Tanaka M, Takizawa H, Satoh M, Okada Y, Yamasawa F, Umeda A. Assessment of an ultrathin bronchoscope that allows cytodiagnosis of small airways. Chest 1994; 106: 1443-1447.

19 Saka H, Oki M, Kitagawa C, et al. Ultrathin bronchoscope in the diagnosis of peripheral lung lesions. Chest 2006; 130: Suppl. 4, 110S-111S.

20 Oki M, Saka H, Sako C, et al. Cavitating invasive pulmonary aspergillosis visualized and diagnosed by ultrathin bronchoscopy. Chest 2006; 129: 475-479.

21 Kvale PA, Bode FR, Kini S. Diagnostic accuracy in lung cancer: comparison of techniques used in association with flexible fiberoptic bronchoscopy. Chest 1976; 69: 752-757.

22 Lam WK, So SY, Hsu C, Yu DY. Fibreoptic bronchoscopy in the diagnosis of bronchial cancer: comparison of washings, brushings and biopsies in central and peripheral tumours. Clin Oncol 1983; 9: 35-42.

23 van der Drift MA, van der Wilt GJ, Thunnissen FB, Janssen JP. A prospective study of the timing and costeffectiveness of bronchial washing during bronchoscopy for pulmonary malignant tumors. Chest 2005; 128: 394-400.

24 Yick D, Kamangar N, Wallace JM. Noninvasive bronchoscopic specimens in the diagnosis of lung cancer. J Bronchol 2001; 8: 301-308.

25 Bandoh S, Fujita J, Tojo Y, et al. Diagnostic accuracy and safety of flexible bronchoscopy with multiplanar reconstruction images and ultrafast Papanicolaou stain: evaluating solitary pulmonary nodules. Chest 2003; 124: 1985-1992.

26 Schwarz Y, Mehta AC, Ernst A, et al. Electromagnetic navigation during flexible bronchoscopy. Respiration 2003; 70: 516-522.

27 Becker HD, Herth F, Ernst A, Schwarz Y. Bronchoscopic biopsy of peripheral lung lesions under electromagnetic guidance: a pilot study. J Bronchol 2005; 12: 9-13. 
28 Gildea TR, Mazzone PJ, Karnak D, Meziane M, Mehta AC. Electromagnetic navigation diagnostic bronchoscopy: a prospective study. Am J Respir Crit Care Med 2006; 174: 982-989.

29 Eberhardt R, Anantham D, Herth F, Feller-Kopman D, Ernst A. Electromagnetic navigation diagnostic bronchoscopy in peripheral lung lesions. Chest 2007; 131: 1800-1805.

30 Makris D, Scherpereel A, Leroy S, et al. Electromagnetic navigation diagnostic bronchoscopy for small peripheral lung lesions. Eur Respir J 2007; 29: 1187-1192.

31 Eberhardt R, Anantham D, Ernst A, Feller-Kopman D, Herth F. Multimodality bronchoscopic diagnosis of peripheral lung lesions: a randomized controlled trial. Am J Respir Crit Care Med 2007; 176: 36-41.

32 Tsushima K, Sone S, Hanaoka T, Takayama F, Honda T, Kubo K. Comparison of bronchoscopic diagnosis for peripheral pulmonary nodule under fluoroscopic guidance with CT guidance. Respir Med 2006; 100: 737-745.

33 Heyer CM, Kagel T, Lemburg SP, et al. Transbronchial biopsy guided by low-dose MDCT: a new approach for assessment of solitary pulmonary nodules. AJR Am J Roentgenol 2006; 187: 933-939.

34 Herth FJ, Ernst A, Becker HD. Endobronchial ultrasoundguided transbronchial lung biopsy in solitary nodules and peripheral lesions. Eur Respir J 2002; 20: 972-974.

35 Shirakawa T, Imamura F, Hamamoto J, et al. Usefulness of endobronchial ultrasonography for transbronchial lung biopsies of peripheral lung lesions. Respiration 2004; 71: 260-268.

36 Kurimoto N, Miyazawa T, Okimasa S, et al. Endobronchial ultrasonography using a guide sheath increases the ability to diagnose peripheral pulmonary lesions endoscopically. Chest 2004; 126: 959-965.

37 Kikuchi E, Yamazaki K, Sukoh N, et al. Endobronchial ultrasonography with guide-sheath for peripheral pulmonary lesions. Eur Respir J 2004; 24: 533-537.

38 Paone G, Nicastri E, Lucantoni G, et al. Endobronchial ultrasound-driven biopsy in the diagnosis of peripheral lung lesions. Chest 2005; 128: 3551-3557.

39 Herth FJ, Eberhardt R, Becker HD, Ernst A. Endobronchial ultrasound-guided transbronchial lung biopsy in fluoroscopically invisible solitary pulmonary nodules: a prospective trial. Chest 2006; 129: 147-150.

40 British Thoracic Society Bronchoscopy Guidelines Committee. British Thoracic Society guidelines on diagnostic flexible bronchoscopy. Thorax 2001; 56: Suppl. 1, i1-i21.

41 Oki M, Saka H, Kitagawa C, et al. Visceral pleural perforation in two cases of ultrathin bronchoscopy. Chest 2005; 127; 2271-2273.

42 Tanaka S, Kajikawa S, Mori K, et al. Is bronchoscopy with a thin bronchoscope more tolerable than with a standard bronchoscope? A retrospective analysis. J Jpn Soc Bronchol 2006; 28: 417-419. 